\title{
Chitosan:Vitamin C Containing Hydrogels as a Prototype Functional Prolonged Pain Management Restorative Material In-Vitro Studies
}

\author{
V. Tamara Perchyonok ${ }^{*}$, Vanessa Reher ${ }^{2}$, Shengmiao Zhang ${ }^{3}$, Theunis Oberholzer ${ }^{2}$, \\ Ward Massey², Sias R. Grobler ${ }^{4}$ \\ ${ }^{1}$ VTPCHEM PTY LTD, Gold Coast, Australia \\ ${ }^{2}$ School of Dentistry and Oral Health, Griffith University, Parkwood, Australia \\ ${ }^{3}$ School of Material Science and Engineering, East China University of Science and Technology, Shanghai, China \\ ${ }^{4}$ Oral and Dental Research Institute, Faculty of Dentistry, University of the Western Cape, Cape Town, \\ South Africa \\ Email: tamaraperchyonok@gmail.com
}

Received 4 June 2014; accepted 20 July 2014; accepted 3 August 2014

Copyright (C) 2014 by authors and Scientific Research Publishing Inc.

This work is licensed under the Creative Commons Attribution International License (CC BY). http://creativecommons.org/licenses/by/4.0/

(c) (i) Open Access

\section{Abstract}

Restorative materials in the new era aim to be "bio-active" and long-lasting. As a part of our continuous interest of developing functional dual action restorative materials capable of being "bioactive" and wound healing, we design and evaluate several novel chitosan-vitamin $C$ (5:1) containing hydrogels as a prototype of host:guest molecular free radical defense material containing hydroethanoic propolis extract (antioxidant containing material), naproxen, ibuprofen (non steroidal anti-inflammatory medication), or aspirin (pain relieve medication and free radical scavengers) as functional restorative materials. We will evaluate the physical properties, bonding to dentin as well as test the bioadhesion of the newly designed materials in order to access the suitability of these prototype materials as suitable restorative materials. Materials and Methods: The hydrogels were prepared by previously reported by us protocol. The physico-chemical features including surface morphology (SEM), release behaviors, stability of the therapeutic agent-antioxidant-chitosan and the effect of the hydrogels on the shear bond strength of dentin were measured and compared to the earlier reported chitosan-antioxidant containing hydrogels. Structural investigations of the reactive surface of the hydrogel were reported. Bio-adhesive studies were performed in order to assess the suitability of these designed materials. Results: Release of aspirin, ibuprofen and naproxen conferred the added benefit of synergistic action of a functional therapeu-

\footnotetext{
${ }^{*}$ Corresponding author.
} 
tic delivery when comparing the newly designed chitosan-based hydrogel restorative materials to the commercially available products alone. Either the release of therapeutic agents or the antioxidant stability was affected by storage over a 12-month period. All chitosan:vitamin C hydrogels showed gave significantly higher shear bond values than dentin treated or not treated with phosphoric acid, which highlighted the feasibility. The bio-adhesive capacity of the materials in the 2 separate "in vitro" systems were tested and quantified. Additional action of chitosan:vitamin C precomplex was investigated and it was found that favourable synergistic effect of free radical build-in defense mechanism of the new functional materials. Conclusion: Additional action of chitosan:vitamin C pre-complex was investigated and it was found that favorable synergistic effect of free radical build-in defense mechanism of the new functional materials, increased dentin bond strength, sustainable bio-adhesion, and acted as a "proof of concept" for the functional multidimensional restorative materials with potential application in wound healing in vitro.

\section{Keywords}

Therapeutic Polymers, Adhesives, Chitosan, Hydrogels, Propolis, Dentin Bonding, Antioxidants, Bioactive and Bioadhesive

\section{Introduction}

Many diseases and pathological syndromes are caused by oxidative stress, i.e. by an imbalance in favor of free radicals. The effect of free radicals, as one of the oldest chemical stimuli and the best organized biological structures such as the central nervous system (CNS), has been relatively seldom studied [1]-[4], of trauma and amyotropical lateral sclerosis. However, information about the influence of free radicals and antioxidants in the CNS during pain is almost completely lacking [5]-[7].

Reactive oxygen species (ROS) are associated with all the stages of the healing process [8]. ROS are produced by the inflammatory cells and play an integral role during this process [9]-[12]. Antioxidants administration is beneficial for healing [13]. It has been suggested that the anti-inflammatory activity of some non-steroidal anti-inflammatory drugs (NSAIDs) may be partly due to their ability to scavenge reactive oxygen species (ROS) [14].

As a part of our continuous interest of developing functional dual action restorative materials capable of being "bio-active" and long-lasting, we design and evaluate novel chitosan:vitamin C hydrogels [15]-[21] as functional additive prototypes for further development of "dual function restorative materials", with the build-in capability of secondly to determine their effect on the dentin bond strength of a composite and thirdly evaluate the bio-adhesive capability of newly designed hydrogels as a "molecular prototype of the site of free radical attack in vitro".

\section{Materials and Methods}

Chitosan:vitamin C (5:1) (Aldrich, Australia), glycerol (Sigma, USA), glacial acetic acid (E. Merck, Germany) were used as received. The degree of de-acetylation of typical commercial chitosan used in this study is $87 \%$. Chitosan with molecular weight $2.5 \times 10^{3} \mathrm{KD}$ was used in the study. The isoelectric point is 4.0 - 5.0. Propolis (Aurora Pharmaceuticals, Australia), Aspirin (Safeway, Australia), Ibuprofen (Safeway, Australia) and Naproxen (Safeway, Australia) were used as received.

\subsection{Preparation of Various Chitosan:Vitamin C Hydrogels Gels: General Protocol}

The therapeutic agent (naproxen, ibuprofen or aspirin) containing gel was prepared by dispersion of naproxen powder $0.4 \mathrm{gm}$ in glycerol $(5 \% \mathrm{w} / \mathrm{w})$ using a mortar and a pestle following the earlier reported generic protocol [27]. Ten milliliters of glacial acetic acid (3\% w/w) was then added with continuous mixing and finally chitosan:vitamin C polymer was spread on the surface of the dispersion and mixed well to form the required gel. The strength of the prepared gel $(10 \mathrm{gm})$ is $0.4 \mathrm{~g}$ (naproxen, ibuprofen or aspirin) in each gram of the base. The 
summary of the newly prepared materials was presented in Table 1.

\subsection{Bioadhesive Study}

Bioadhesion studies were done using chatillon apparatus for force measurement [22]. This method determines the maximum force and work needed to separate two surfaces in intimate contact [22]. The hydrogels (0.1 g) were homogeneously spread on a $1 \mathrm{~cm}^{2}$ glass disk and then the disks were fixed to the support of the tensile strength tester using double side adhesive. The gel was brought into contact with the commercially available band aid, in order to simulate the skin attachment or the contact with slice of dentin was established in order to imitate adhesion of the gel to the tooth structure, after a preset contact time ( $1 \mathrm{~min})$ under contact strength (0.5 $\mathrm{N}$ ) the 2 surfaces were separated at a constant rate of displacement $(1 \mathrm{~mm} / \mathrm{s})$. The strength was recorded as a function of the displacement, which allowed to determine the maximal detachment force, Fmax, and the work of adhesion, $\mathrm{W}$, which was calculated from the area under the strength-displacement curve.

\subsection{Assessment of the Flavonoid Content in Propolis}

The procedure for the investigation was adapted from the literature [23]. Flavonoids in propolis hydroalcoholic extracts were expressed as quercetine equivalent. Quercetine (Sigma, Germany) was used to make the calibration curve (standard solutions of 6.25, 12.5, 25.0, 50.0, 80.0 and $100.0 \mathrm{~g} \cdot \mathrm{mL}^{-1}$ in $80 \%$ ethanol (V/V)). $0.5 \mathrm{~mL}$ of a product (ethanolic solutions of propolis) was mixed with $1.5 \mathrm{~mL} 95 \%$ ethanol (V/V), $0.1 \mathrm{~mL} 10 \%$ aluminum chloride $(\mathrm{m} / \mathrm{V}), 0.1 \mathrm{~mL}$ of $1 \mathrm{~mol} \cdot \mathrm{L}^{-1}$ potassium acetate and $2.8 \mathrm{~mL}$ water. A volume of $10 \%(\mathrm{~m} / \mathrm{V})$ aluminum chloride was substituted by the same volume of distilled water in blank. After incubation at room temperature for $30 \mathrm{~min}$, the absorbance of the reaction mixture was measured at $415 \mathrm{~nm}$.

\subsection{Determination of Gel pH}

One gram of the prepared gels was accurately weighed and dispersed in $10 \mathrm{~mL}$ of purified water. The $\mathrm{pH}$ of the dispersions was measured using a pH meter (HANNA instruments, HI8417, Portugal).

\subsection{In Vitro Study of Therapeutic Agent Release Profile: General Protocol}

The release study was carried out with USP dissolution apparatus type 1, Copley UK, slightly modified in order to overcome the small volume of the dissolution medium, by using $100 \mathrm{~mL}$ beakers instead of the jars. The basket of the dissolution apparatus $(2.5 \mathrm{~cm}$ in diameter) was filled with $1 \mathrm{gm}$ of asprin gel on a filter paper. The basket was immersed to about $1 \mathrm{~cm}$ of its surface in $50 \mathrm{~mL}$ of phosphate buffer $\mathrm{pH} 6.8$, at $37^{\circ} \mathrm{C} \pm 0.5$ and 100 rpm [24]. Samples (2 mL) were collected at 0.25 - 24 hours hours [25] and were analyzed spectro-photometrically by U.V. Spectrophotometer (Cintra 5, GBC Scientific equipment, Australia) at $\lambda$ max $275 \mathrm{~nm}$ (aspirin), $\lambda$ $\max 264 \mathrm{~nm}$ (for ibuprofen), and $\lambda \max 260 \mathrm{~nm}$ (for naproxen) [26]. Each sample was replaced by the same volume of phosphate buffer pH 6.8 to maintain its constant volume and sink condition [27].

Table 1. Gel formulation prepared in the study.

\begin{tabular}{|c|c|c|c|c|c|c|c|}
\hline Gel formulation & & Chitosan:vit C 5:1 (w/w\%) & Aspirin (w/w\%) & Propolis (w/w) & Ibuprofen & Naproxen & pH \\
\hline Chitosan-vit C (5:1) & Gel 1 & 5 & 0 & 0 & 0 & 0 & 5.64 \\
\hline Chitosan-vit C-A1 & Gel 2 & 5 & 1 & 0 & 0 & 0 & 5.85 \\
\hline Chitosan-vit C-A1P & Gel 3 & 5 & 1 & 1 & 0 & 0 & 6.10 \\
\hline Chitosan-vit C-N1 & Gel 4 & 5 & 0 & 0 & 0 & 1 & 5.95 \\
\hline Chitosan-vit C-N1P1 & Gel 5 & 5 & 0 & 1 & 0 & 1 & 6.27 \\
\hline Chitosan-vit C-I1 & Gel 6 & 5 & 0 & 0 & 1 & 0 & 6.20 \\
\hline Chitosan-vit C-I1P1 & Gel 7 & 5 & 0 & 0 & 1 & 1 & 5.98 \\
\hline
\end{tabular}

Where $\mathrm{P}$ is propolis additive, $\mathrm{A}$ is aspirin additive, $\mathrm{N}$ is the naproxen, $\mathrm{I}$ is ibuprofen. Hydrogels containing chitosan:vitamin $\mathrm{C}$ (5:1) (5\%) are synthesized and characterized. 


\subsection{Morphology of the Gels}

The samples were prepared by freezing in liquid nitrogen for $10 \mathrm{~min}$, and then were freeze-dried for $24 \mathrm{~h}$. The prepared samples were fractured in liquid nitrogen using a razor blade. The fractured samples were attached to metal stubs, and sputter coated with gold under vacuum for SEM. The interior and the surface morphology were observed in scanning electron microscope (SEM, Hitachi S4800, Japan).

\subsection{Gel Stability}

Stability of the gel formulations was also investigated. The organoleptic properties (color, odor), $\mathrm{pH}$, drug content, and release profiles of the gels stored at $20^{\circ} \mathrm{C}$ were examined on days $(0,15,30$ and 178) [27].

\subsection{Studies of Equilibrium Swelling in the Alternative Drug Delivery Systems}

A known weight functionalized chitosan containing dry gels were immersed in $\mathrm{pH} 4.0, \mathrm{pH} 9.0$ buffer solutions, respectively, and kept at $25^{\circ} \mathrm{C}$ for $48 \mathrm{~h}$ until equilibrium of swelling had been reached as previously described [27]. The swollen gels were taken out and immediately weighed with microbalance after the excess of water lying on the surfaces was absorbed with a filter paper. The equilibrium swelling ratio (SR) was calculated using the following equation:

$$
\mathrm{SR}=\left(\mathrm{W}_{\mathrm{s}}-\mathrm{W}_{\mathrm{d}}\right) / \mathrm{W}_{\mathrm{d}} \times 100 \%
$$

where $\mathrm{W}_{\mathrm{s}}$ and $\mathrm{W}_{\mathrm{d}}$ are the weights of the gels at the equilibrium swelling state and at the dry state, respectively [28]. Experiments were repeated in triplicate for each gel specimen and the mean value calculated.

\subsection{Shear Bond Strength Tests for Dentin Bonding}

Extracted non-carious, intact, human molars stored in water containing a few crystals of thymol at $4^{\circ} \mathrm{C}$ were used within two months using protocol previously described by us [27].

80 teeth samples (each containing 2 studs) prepared and divided into 10 groups of 8 each, A-N (Table 2) and stored in a solution of artificial saliva. These groups were then treated as outlined in Table 2. After 24 hours one stud of each tooth was tested for shear bond strength and the other one after 3 months. An Instron Universal Testing Machine at a crosshead speed of $0.5 \mathrm{~mm} /$ minute was used to test the de-bonding strength. All data tests were analyzed using the non-parametric ANOVA test.

\section{Discussion}

\subsection{Propolis Extracts and Flavonoid Content}

On the basis of calibration curve for standard flavonoids, the concentration of these bioactive compounds in the hydroalcoholic extracts of the propolis sample used in the study was assessed. The content of flavonoids of the

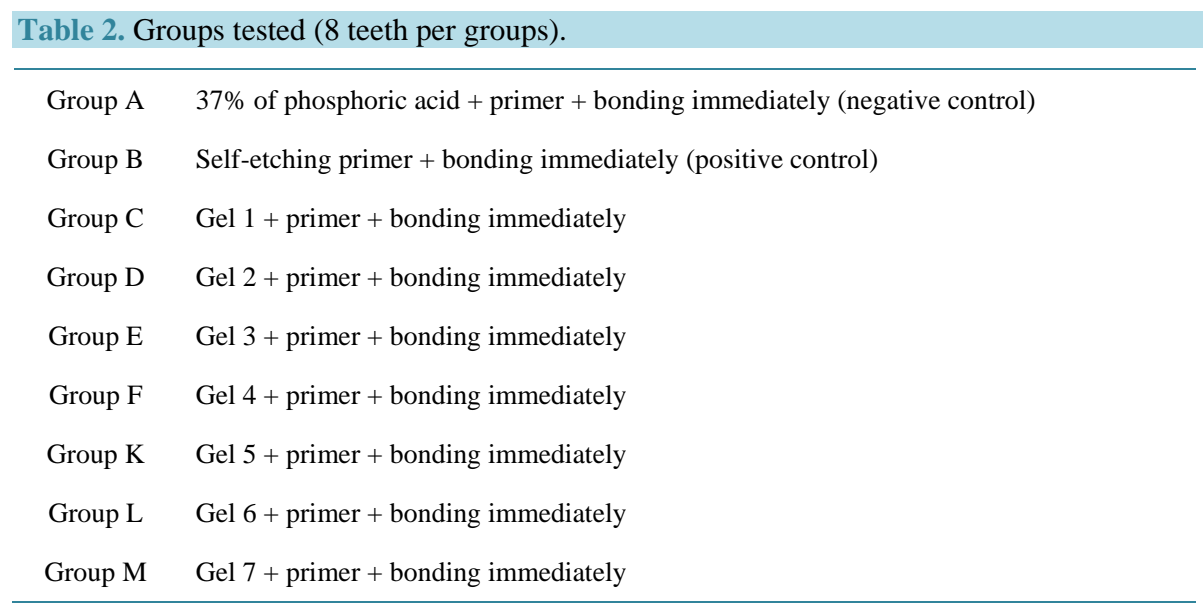


propolis was $1.23 \% \pm 0.35 \%$, which is consistent with the previously reported values for a hydroalcoholic extracts of the propolis in the literature [28]. The flavonoid content of the propolis extracts is the major contributing factor in biological activity of the propolis. The biological effects of flavonoids can be subdivided into 4 categories: a) binding affinity to biological polymers, b) binding of heavy metal ions, c) catalyst of electron transport and d) ability to scavenge free radicals [29]. The proposed mechanism of the propolis and its ability to mediate the inflammatory response in vivo have been previously explored in some details and suggested that the healing properties of propolis can be directly correlated with anti-oxidant potential as well as anti-inflammatory properties of flavonoids [30]. The work is currently on the way in our laboratories to evaluate the mechanism in vitro and in vivo in great details.

\subsection{The Characterization of NSAID-Chitosan Gels (Gel 1-8)}

The SEM images were obtained to characterize the microstructure of the freeze-dried naproxen composite gels and are presented in Figure 1. It was thought that the micro-porous structure of the gels could lead to high internal surface areas with low diffusional resistance in the gels. The surfaces of the gels were also presented (Figure 1). The "skin" of the gels can be seen, and the collapse of the surface pores may be due to freeze-drying process.

\subsection{Studies of Equilibrium Swelling in NSAIDs-Chitosan:Vitamin C Gels (Gel 1-7)}

The hydrogels remain in the cylindrical form after swelling. Compared with dry state hydrogels, the swollen state hydrogel volume displays significant increases and are summarized in Figure 2.

Equilibrium swelling ratio (SR) of hydrogels exerts an influence on their release rates. The reduction in equilibrium swelling capacity is due to the formation of a tight network structure in high content. Environmental pH value has a large effect on the swelling behavior of these gels. From Figure 2, it is clear that the SR value increases with the increase of $\mathrm{pH}$. Such $\mathrm{pH}$ dependent properties of the hydrogels come from the polyelectrolyte nature of chitosan segments in the hydrogel network. Namely, when the pH value of the buffer solution (pH 9.0) was far higher than the isoelectric point (PI) of the hydrogels prepared, the carboxyl groups were de-protonized to carry negative charges, which made molecular chains repulsed to each other. The network became looser and it was easy for the water molecules to diffuse into the cross-linked network. Additionally chitosan:vitamin $\mathrm{C}$ host:guest complex represents the additional benefit of the expanding the functionality of these materials and the in depth investigation of the mechanism is currently under investigation in our laboratories and will be reported in due cause.

\subsection{Shear Bond Strengths}

Figure 3 gives the shear bond strength values (MPa) after 24 hours.

Mean shear bond strength values and difference between the groups are summarized in Figure 3 for bonding to dentin after 24 hours and in Figure 4 for bonding after 3 month. In general there was an increase in bond strength of the dentin treated with the antioxidant (chitosan:vit C complex) containing hydrogels compared to the bond strength of the conventionally bonded teeth. An increase in the shear bond strength was also previously reported [31] for chitosan-vit C, chitosan/vit C-aspirin, chitosan-vit C-aspirin-propolis, chitosan-vit C-naproxen, chitosan-vit C-naproxen-propolis, chitosan-vit C-ibuprofen and chitosan:vit C:ibuprofen:propolis. Interestingly the increase in bond strength was also observed in the groups of hydrogen peroxide exposed samples suggesting that there additional benefits associated with chitosan:antioxidant system are in need of further investigations [31].

The results of this study suggests that the optimum results for the strengthening of dentin can be achieved throughout the immediate treatment with antioxidant:chitosan:vitamin C "host:guest” complex with the increase of dentin bond strength. The additional advantage of the system may suggest that, antioxidant release from chitosan gel depends on the physical host:guest structure as well as $\mathrm{pH}$ properties and flexibilities of the material. Antioxidant release occurs through the pores of the low polymer concentration while chitosan concentration increment resulted in more cross-linking of the network structure; consequently slower antioxidant release from the gel base was achieved and there for weaker adhesive properties of the materials such as Gel 1 in case of groups [32]-[34]. The additional benefit of using chitosan:antioxidant system as a bonding/pre-bonding to 


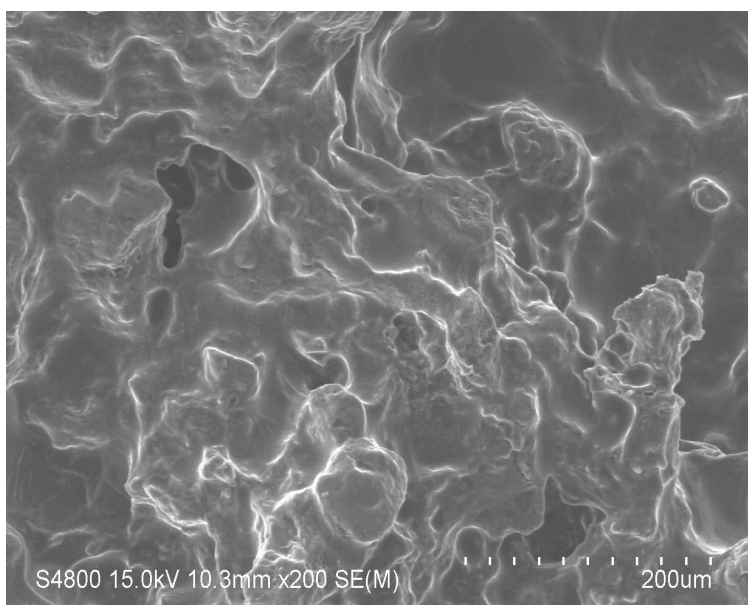

Chit/Vit C/Ib/Propolis

(a)

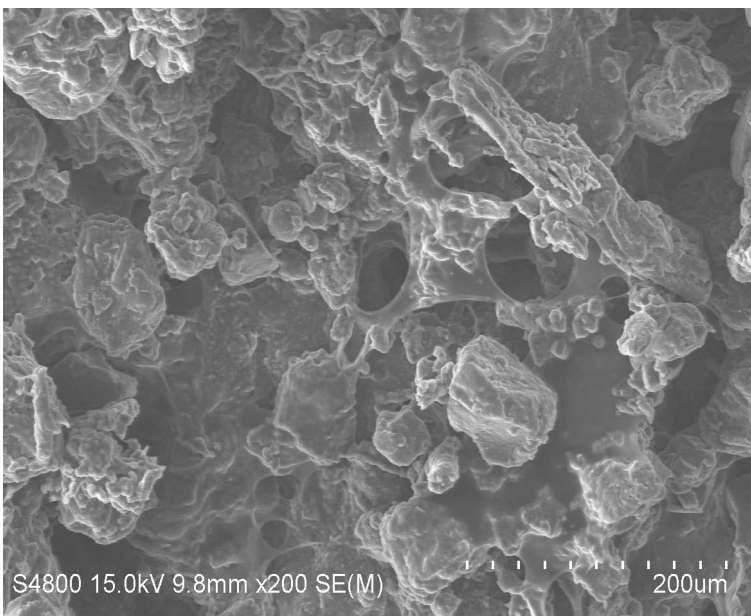

Chit/Vit C/Nap/Propolis

(c)

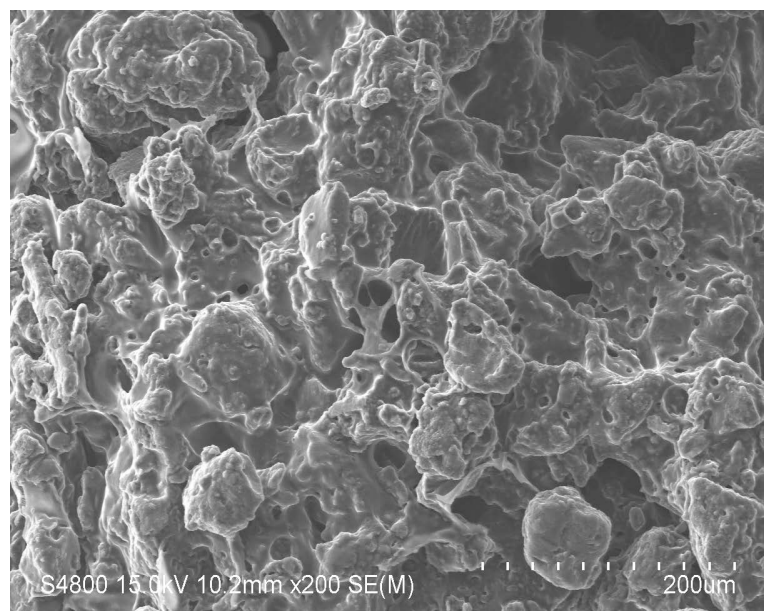

Chit/Vit C/Asp/Propolis

(e)

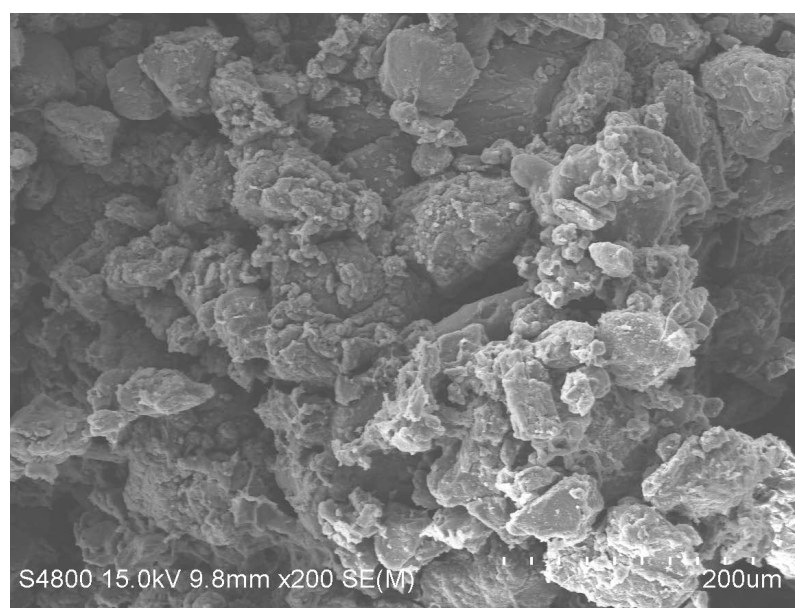

Chit/Vit C/Ib

(b)

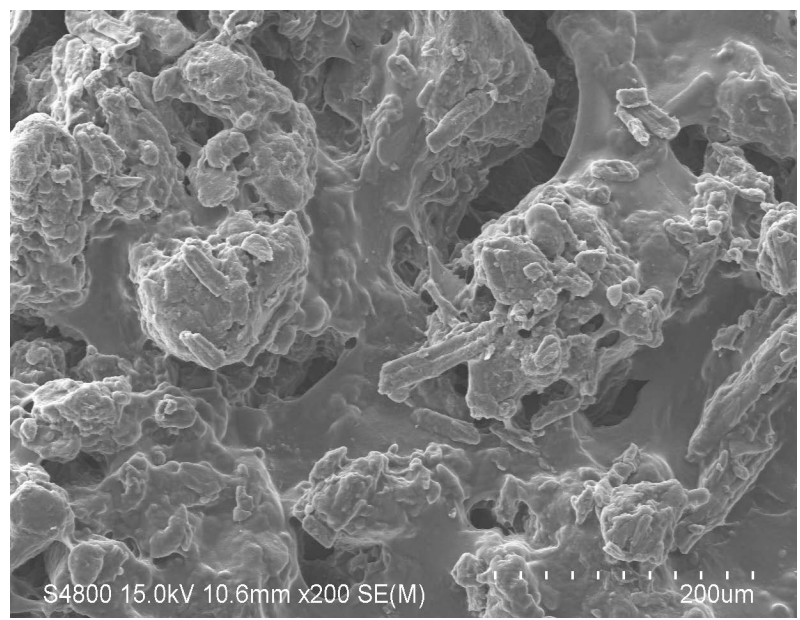

Chit/Vit C/Nap

(d)

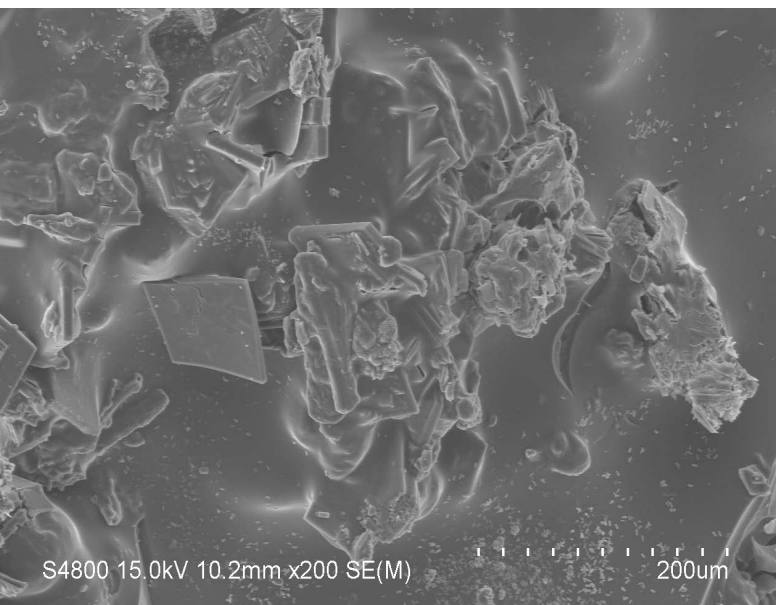

Chit/Vit C/Asp

(f)

Figure 1. SEM photographs of interior morphology of the selected gels under investigation for (a) Gel 2, (b) Gel 3, (c) Gel 4, (d) Gel 5, (e) Gel 6, (f) Gel 7. 


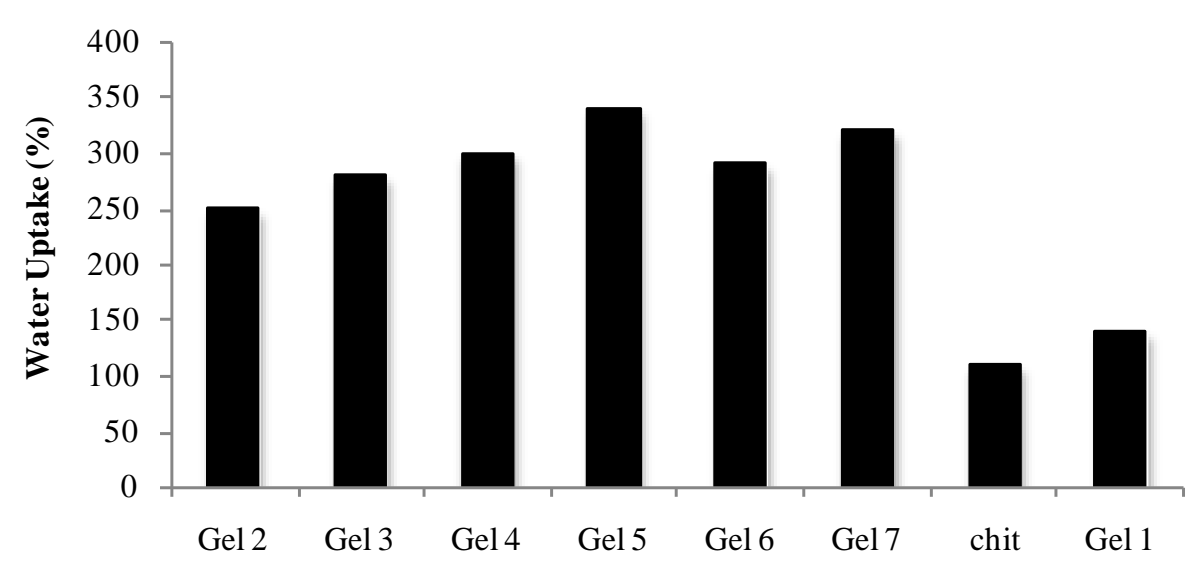

Figure 2. Water uptake degree of the gels Gel 1-Gel $7(n=6, p<0.05)$.

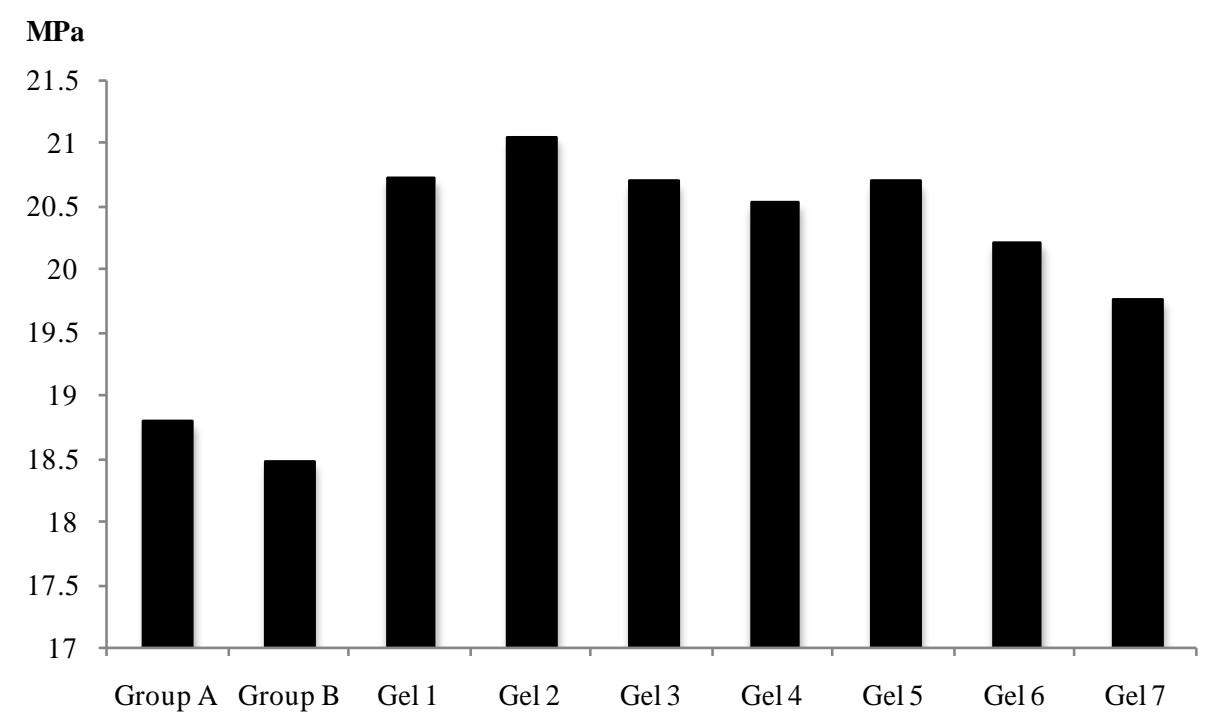

Figure 3. Shear bond strength of hydrogels after 24 hours of bonding to dentin.

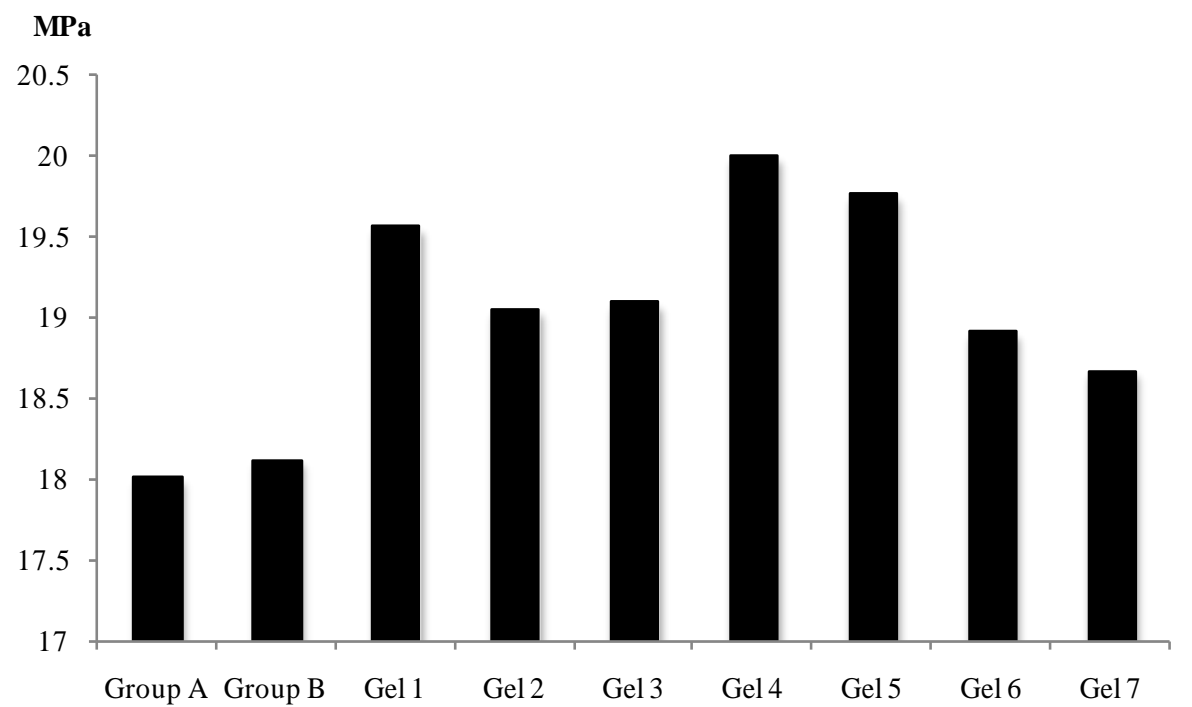

Figure 4. Shear bond strength of hydrogels after 3 month of bonding to dentin. 
enamel and dentin system lies in its ability to show favorable immediate results in terms of bonding effectiveness as well as the durability of resin-dentin bonds for a prolonged time (up to 6 months) [27] [34]. It is well documented that the hydrostatic pulpal pressure, the dentinal fluid flow and the increased dentinal wetness in vital dentin can affect the intimate interaction of certain enamel and dentin adhesives with dentinal tissue [27] [34] [38]. Therefore the newly developed chitosan:antioxidant (combination of vitamin C and propolis) systems, are supporting our earlier reported results [27] be able to address the shortfalls affecting the long-term bonding performance of modern adhesives and addresses the current perspectives for improving bond durability of conventional adhesive systems.

\subsection{In Vitro Release of the Therapeutic Agent from Chitosan/Vit C Gels}

The in vitro release of therapeutic agent such as (naproxen, ibuprofen and aspirin) from chitosan:vitamin C hydrogelsgels. The cumulative release studies as shown in Figures 5-7. Its becomes apparent that the influence of chemical structures of antioxidants such as vitamin $C$ and propolis have significantly improved the release of naproxen, Ibuprofen and asprin from the hydrogels. The mechanism of this interaction is currently under investigations in our laboratories.

\subsection{Stability of Antioxidants Such as (Propolis, Aspirin, Naproxen and Ibuprofen) in the Chitosan:Vitamin C Hydrogels during Storage}

Stability of various conventional antioxidants in the newly designed drug delivery system during storage is an important factor to determine whether chitosan-coated nano-size delivery vehicle can protect various conventional antioxidants. So the stability of the microencapsulated antioxidants has been measured by UV absorbance. Stabilities of microencapsulated antioxidants have been compared and after 6 month of storage at $24^{\circ} \mathrm{C}$, the stability of antioxidant-molecular carrier vehicle was over $95 \%$. This indicated that the antioxidant had been protected by the molecular carrier such as chitosan:vitamin C complex. Important to note that performance of the antioxidant was enhanced by the presence of the chitosan, which is a very interesting point in itself as the synergism in increased stability and lower concentration of the active antioxidant wit the same or even higher antioxidant capacity can lead to a development of broad range to novel functional drug delivery systems. Surfaces of the material were also examined and the SEM images are summarized in Figure 8.

The in-depth investigation of interaction between $\mathrm{Fe}^{3+} / \mathrm{Fe}^{2+}$ and functional chitosan biomaterials are currently on the way in our laboratory and will be reported in due course.

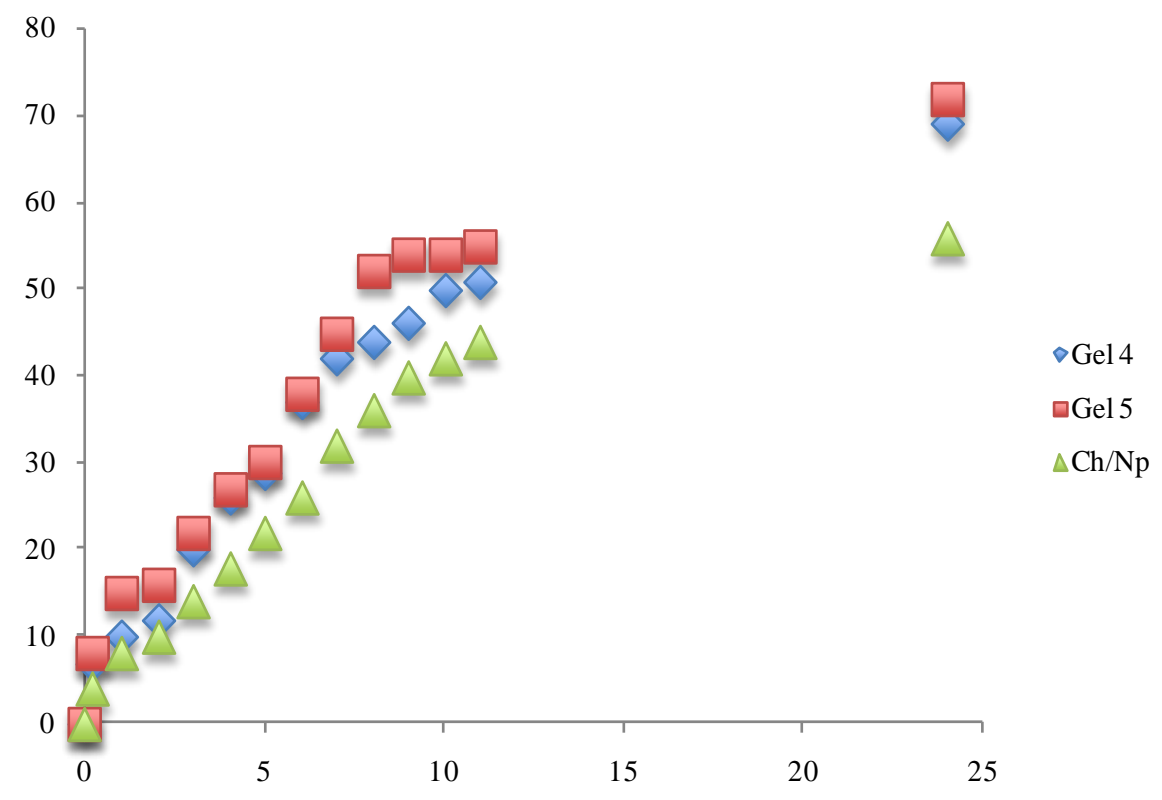

Figure 5. The effect additive such as propolis and vitamin $\mathrm{C}$ release from $5 \% \mathrm{w} / \mathrm{w}$ chitosan gels (Gel 4 and Gel 5) in phosphate buffer $\mathrm{pH} 6.8$. 


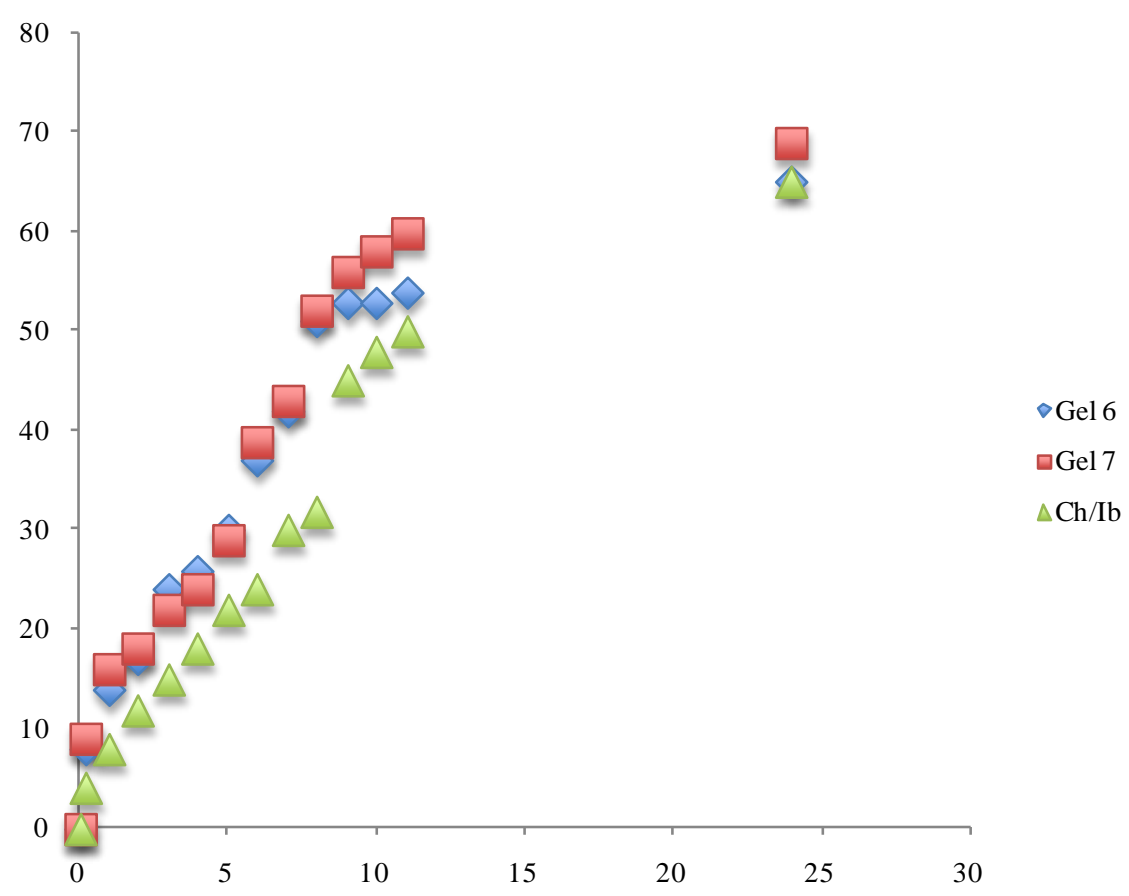

Figure 6. The effect additive such as propolis and chitosan release of ibuprofen.

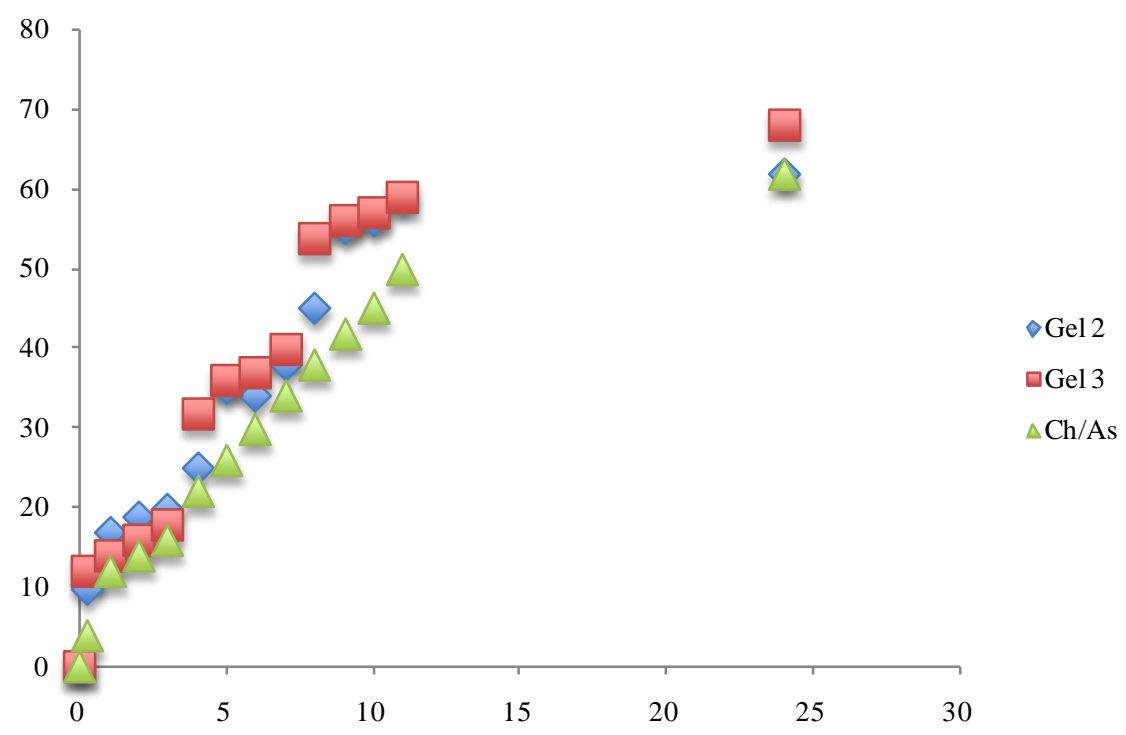

Figure 7. The effect additive such as propolis and chitosan release from $5 \% \mathrm{w} / \mathrm{w}$ chitosan gels in phosphate buffer $\mathrm{pH}$ 6.8.

\subsection{Bio-Adhesion in Vitro Model}

Higher adhesiveness of the gels is desired to maintain an intimate contact with skin or tooth structure and results are summarized in Table 3. Chitosan hydrogels showed the highest adhesive force and the work of adhesion this can be expected because of the well known intrinsic bioadhesive properties of chitosan [35]. The adequate water absorption capacity together with the cationic nature which promotes binding to the negative surface of skin or dentin structure can also interpret these results.

Chitosan hydrogels showed the highest adhesive force and the work of adhesion this can be expected because of the well known intrinsic bioadhesive properties of chitosan. The adequate water absorption capacity together 


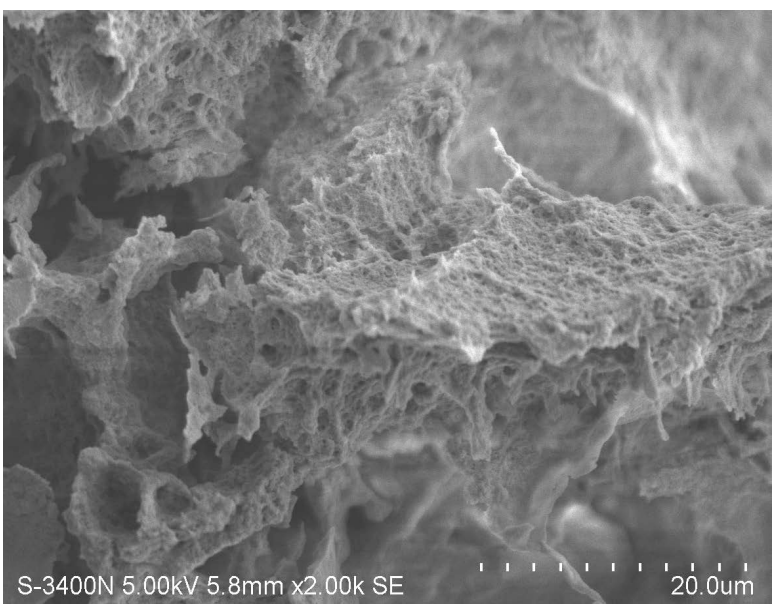

$\mathrm{Ch} / \mathrm{Vit} \mathrm{C} / \mathrm{As}$ exposed to peroxide

(a)

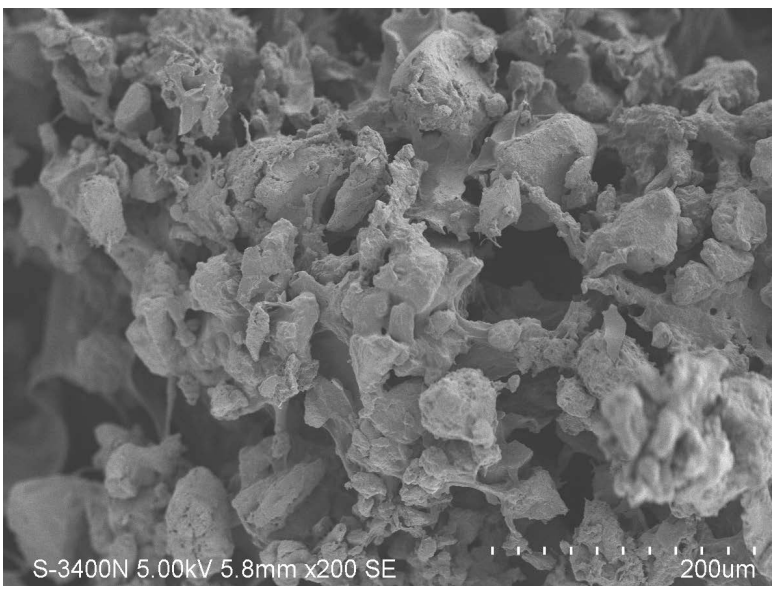

$\mathrm{Ch} / \mathrm{Vit} \mathrm{C} / \mathrm{Nap}$ exposed to peroxide

(c)

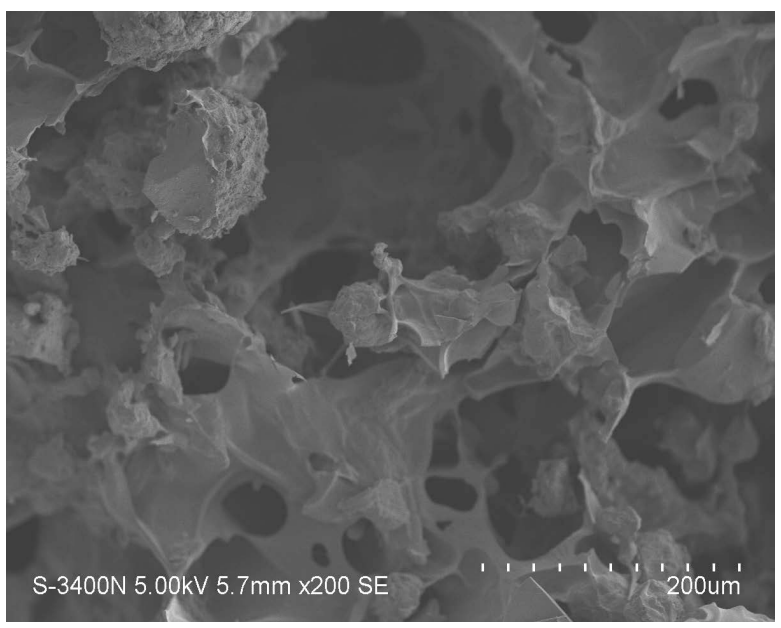

$\mathrm{Ch} / \mathrm{Vit} \mathrm{C} / \mathrm{Ib}$ exposed to peroxide

(e)

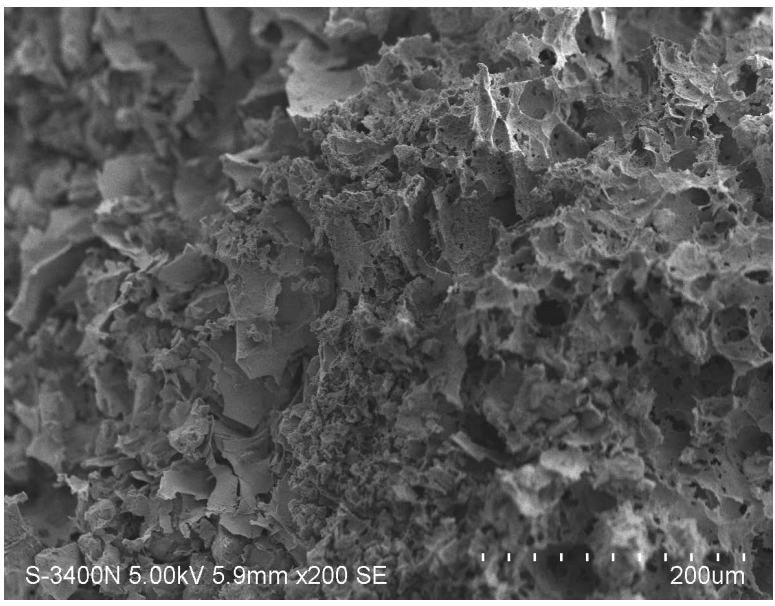

Ch/Vit C/As/Propolis exposed to peroxide

(b)

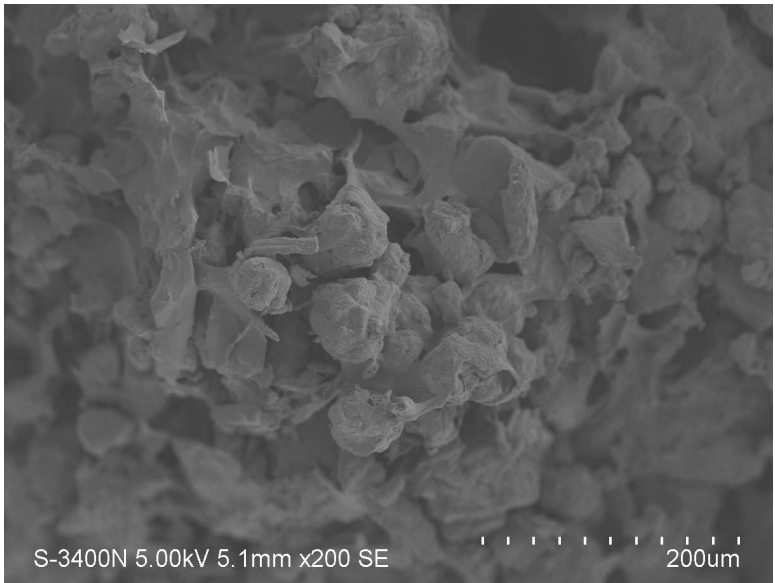

$\mathrm{Ch} / \mathrm{Vit} \mathrm{C} / \mathrm{Nap} / \mathrm{Krill}$ exposed to peroxide

(d)

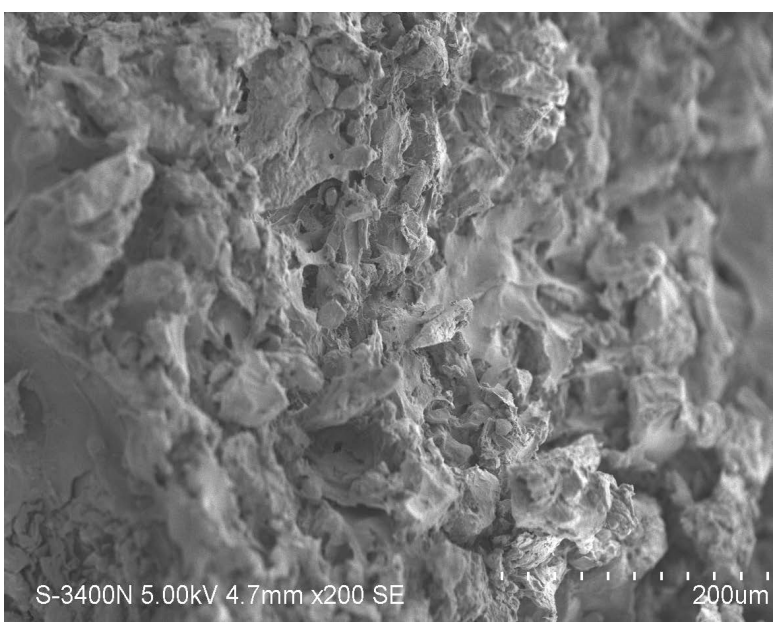

$\mathrm{Ch} / \mathrm{Vit} \mathrm{C} / \mathrm{Ib} /$ Propolis exposed to peroxide

(f)

Figure 8. SEM images of reactive surfaces of novel biomaterials after the exposure to peroxide and "in vitro model of free radical damage”. 
Table 3. Bioadhesion testing in vitro.

\begin{tabular}{|c|c|c|c|c|}
\hline Hydrogel & $\begin{array}{l}\text { Adhesive force } \\
\text { (N) } \pm \text { SD (skin) }\end{array}$ & $\begin{array}{l}\text { Adhesive force } \\
(\mathrm{N}) \pm \mathrm{SD} \text { (dentin) }\end{array}$ & $\begin{array}{l}\text { Work of adhesion } \\
(\mathrm{N} \mathrm{cm}) \pm \mathrm{SD} \text { (skin) }\end{array}$ & $\begin{array}{c}\text { Work of adhesion } \\
(\mathrm{N} \mathrm{cm}) \pm \mathrm{SD} \text { (dentin) }\end{array}$ \\
\hline Gel 1 & $1.15 \pm 0.40$ & $1.09 \pm 0.35$ & $3.35 \pm 0.48$ & $2.92 \pm 0.34$ \\
\hline Gel 2 & $1.07 \pm 0.25$ & $1.17 \pm 0.42$ & $3.19 \pm 0.52$ & $3.49 \pm 0.42$ \\
\hline Gel 3 & $0.97 \pm 0.30$ & $0.99 \pm 0.40$ & $2.85 \pm 0.41$ & $2.94 \pm 0.29$ \\
\hline Gel 4 & $1.10 \pm 0.34$ & $1.09 \pm 0.24$ & $3.31 \pm 0.31$ & $3.38 \pm 0.31$ \\
\hline Gel 5 & $1.08 \pm 0.28$ & $1.11 \pm 0.26$ & $3.49 \pm 0.31$ & $3.35 \pm 0.28$ \\
\hline Gel 6 & $0.89 \pm 0.45$ & $0.96 \pm 0.41$ & $2.55 \pm 0.46$ & $2.98 \pm 0.21$ \\
\hline Gel 7 & $1.12 \pm 0.29$ & $1.23 \pm 0.30$ & $3.48 \pm 0.46$ & $3.81 \pm 0.28$ \\
\hline
\end{tabular}

The presented values are an average $(\mathrm{n}=5)$.

with the cationic nature, which promotes binding to the negative surface of skin or dentin structure can also interpret this results. According to Caffaggi, hydration of the polymer causes mobilization of the polymer chains and hence influences polymeric adhesion [36]. Appropriate swelling is important to guarantee adhesivity; however, over hydration can form slippery non-adhesive hydrogels [37]. In addition the molecular arrangement of the polymeric chains, which are present in the new hydrogels, such as propolis, aspirin, ibuprofen and naproxen can further unable to interact further with the substrate. The correlation between the force and work of adhesion is noticeable for all. Further experiments are to be conducted on the skin samples to evaluate the bio-adhesive capacity of the designed hydrogels.

\section{Conclusion}

The materials were tested using effective in-vitro free radical generation model as functional additive prototypes for further development of "dual function restorative wound healing materials". We quantified the effects of functional designed biomaterials on the dentin bond strength of a composite and evaluated the bio-adhesive capacity of the materials in the 2 separate "in vitro" systems. The added benefits of the chitosan:vitamin C host:guest complex treated hydrogels involved positive influence on the aspirin, ibuprofen and naproxen release, increased dentin bond strength as well as demonstrated in vitro "build-in" free radical defense mechanism and therefore acted as a "proof of concept" for the functional multi-dimensional restorative would healing materials with the build-in free radical defense mechanism.

\section{Disclosure}

Preliminary results of the performance of chitosan hydrogel (Gel 1) was reported by us in Open Journal of Stomatology, Vol. 4, No. 2 (2014), Article ID: 43159.

\section{References}

[1] Fu, X., Fang, L., Li, H., Li, X., Cheng, B. and Sheng, Z. (2007) Adipose Tissue Extract Enhances Skin Wound Healing. Wound Repair Regeneration, 15, 540-548. http://dx.doi.org/10.1111/j.1524-475X.2007.00262.x

[2] Alborova, A., Lademann, J., Meye, L., Kramer, A., Patzelt, A., Sterry, W. and Antoniou, C. (2007) Application of Laser Scanning Microscopy for the Characterization of Wound Healing. GMS Krankenhaushygiene Interdisziplinär, 2, 37.

[3] Barbosa de Almeida, E., Cordeiro Cardoso, J., Karla de Lima, A., Lucas de Oliveira, N., Teles de Pontes-Filho, N., Oliveira Lima, S., Leal Souza, I.C. and Cavalcanti de Albuquerque-Junior, R.L. (2013) Incorporation of Brazilian Propolis into Collagen-Based Dressing Films Improves Dermal Burn Healing. Journal of Ethnopharmacology, 147, 419425. http://dx.doi.org/10.1016/j.jep.2013.03.031

[4] Lefer, L.A. (1966) Psychoanalytic View of a Dental Phenomenon. Contemporary Psychoanalysis, 2, 135-136. http://dx.doi.org/10.1080/00107530.1966.10745103

[5] Fine, E.W. (1971) Psychological Factors Associated with Non-Organic TMJ Dysfunction Syndrome. British Dental Journal, 131, 402-427. http://dx.doi.org/10.1038/sj.bdj.4802760 
[6] Feinmann, C. and Harris, M. (1984) Psychogenic Facial Pain. 1. The Clinical Presentation. British Dental Journal, 156, 165-168. http://dx.doi.org/10.1038/sj.bdj.4805298

[7] Feinmann, C. and Harris, M. (1984) Psychogenic Facial Pain. Management and Prognosis. British Dental Journal, 156, 205-208. http://dx.doi.org/10.1038/sj.bdj.4805304

[8] Aghabeigi, B., Feinmann, C., Glover, V., et al. (1993) Tyramine Conjugation Deficit in Patients with Chronic Idiopathic Temporomandibular Joint and Orofacial Pain. Pain, 54, 159-163. http://dx.doi.org/10.1016/0304-3959(93)90204-3

[9] Fundueanu, G., Constantin, M. and Ascenzi, P. (2008) Preparation and Characterization of pH- and Temperature-Sensitive Pullulan Microspheres for Controlled Release of Drugs. Biomaterials, 29, 2767-2775. http://dx.doi.org/10.1016/j.biomaterials.2008.03.025

[10] Huynh, D.P., Nguyen, M.K., Pi, B.S., Kim, M.S., Chae, S.Y., Lee, K.C., et al. (2008) Functionalized Injectable Hydrogels for Controlled Insulin Delivery. Biomaterials, 29, 2527-2534. http://dx.doi.org/10.1016/j.biomaterials.2008.02.016

[11] Wang, Y.C., Liu, X.Q., Sun, T.M., Xiong, M.H. and Wang, J. (2008) Functionalized Micelles from Block Copolymer of Polyphosphoester and Poly( $\varepsilon$-Caprolactone) for Receptor-Mediated Drug Delivery. Journal of Controlled Release, 128, 32-40. http://dx.doi.org/10.1016/j.jconrel.2008.01.021

[12] Nakamura, K., Maitani, Y., Lowman, A.M., Takayama, K., Peppas, N.A. and Nagai, T. (1999) Uptake and Release of Budesonide from Mucoadhesive, $\mathrm{pH}$-Sensitive Copolymers and Their Application to Nasal Delivery. Journal of Controlled Release, 61, 329-335. http://dx.doi.org/10.1016/S0168-3659(99)00150-9

[13] Mok, H., Park, J.W. and Park, T.G. (2008) Enhanced Intracellular Delivery of Quantum Dot and Adenovirus Nanoparticles Triggered by Acidic $\mathrm{pH}$ via Surface Charge Reversal. Bioconjugate Chemistry, 19, 797-801. http://dx.doi.org/10.1021/bc700464m

[14] He, C., Kim, S.W. and Lee, D.S. (2008) In Situ Gelling Stimuli-Sensitive Block Copolymer Hydrogels for Drug Delivery. Journal of Controlled Release, 127, 189-207. http://dx.doi.org/10.1016/j.jconrel.2008.01.005

[15] Bae, Y. and Kataoka, K. (2006) Significant Enhancement of Antitumor Activity and Bioavailability of Intracellular pH-Sensitive Polymeric Micelles by Folate Conjugation. Journal of Controlled Release, 116, e49-e50. http://dx.doi.org/10.1016/j.jconrel.2006.09.044

[16] Kim, J., Conway, A. and Chauhan, A. (2008) Extended Delivery of Ophthalmic Drugs by Silicone Hydrogel Contact Lenses. Biomaterials, 29, 2259-2269. http://dx.doi.org/10.1016/j.biomaterials.2008.01.030

[17] McLennan, S.V., Bonner, J., Milne, S., Lo, L., Charlton, A., Kurup, S., Jia, J., Yue, D.K. and Twigg, S.M. (2008) The Anti-Inflammatory Agent Propolis Improves Wound Healing in a Rodent Model of Experimental Diabetes. Wound Repair Regeneration, 16, 706-713. http://dx.doi.org/10.1111/j.1524-475X.2008.00421.x

[18] Ramos, A.F.N. and Miranda, J.L. (2007) Propolis: A Review of Its Anti-Inflammatory and Healing Actions. Journal of Venomous Animals and Toxins Including Tropical Diseases, 13, 697-710. http://dx.doi.org/10.1590/S1678-91992007000400002

[19] Rich, L. and Whitaker, P. (2005) Collagen and Picrosirius Red Staining: A Colorized Light Assessment of Fibrillar Hue and Spatial Distribution. Journal of Morphological Science, 22, 97-104.

[20] Ribeiro, M.A., Albuquerque, R.L., Ramalho, L.M., Pinheiro, A.L., Bonjardim, L.R. and Da Cunha, S.S. (2009) Immunohistochemical Assessment of Myofibroblasts and Lymphoid Cells during Wound Healing in Rats Subjected to Laser Photobiomodulation at $660 \mathrm{~nm}$. Photomedicine and Laser Surgery, 27, 49-55. http://dx.doi.org/10.1089/pho.2007.2215

[21] Sehn, E., Hernandes, L., Franco, S.L., Gonçalves, C.C. and Baesso, M.L. (2009) Dynamics of Reepithelialisation and Penetration Rate of Bee Propolis Formulation during Cutaneous Wounds Healing. Analytica Chimica Acta, 635, 115120. http://dx.doi.org/10.1016/j.aca.2009.01.019

[22] Mathiowitz, E. and Chickering III, D.E. (2010) Definitions, Mechanisms, and Theories of Bioadhesion. In: Mathiowitz, E., Chickering III, D.E. and Lehr, C.M., Eds., Bioadhesive Drug Delivery Systems, Fundamentals, Novel Approaches, and Development, Marcel Dekker Inc., New York, 4-8.

[23] Chen, S., Li, Y., Guo, C., Wang, J., Ma, J., Liang, X., et al. (2007) Temperature-Responsive Magnetite/PEO-PPO-PEO Block Copolymer Nanoparticles for Controlled Drug Targeting Delivery. Langmuir, 23, 12669-12676. http://dx.doi.org/10.1021/la702049d

[24] Shah, N.M., Pool, M.D. and Metters, A.T. (2006) Influence of Network Structure on the Degradation of Photo-CrossLinked PLA-b-PEG-b-PLA Hydrogels. Biomacromolecules, 7, 3171-3177. http://dx.doi.org/10.1021/bm060339z

[25] Nolkrantz, K., Farre, C., Brederlau, A., Karlsson, R.I.D., Brennan, C., Eriksson, P.S., et al. (2001) Electroporation of Single Cells and Tissues with an Electrolyte-Filled Capillary. Analytical Chemistry, 73, 4469-4477. http://dx.doi.org/10.1021/ac010403x 
[26] Nguyen, K.T. and West, J.L. (2002) Photopolymerizable Hydrogels for Tissue Engineering Applications. Biomaterials, 23, 4307-4314. http://dx.doi.org/10.1016/S0142-9612(02)00175-8

[27] Perchyonok, V.T., Reher, V., Zhang, S., Grobler, S.R., Oberholzer, T.G. and Massey, W. (2014) Insights and Relative Effect of Aspirin, Naproxen and Ibuprofen Containing Hydrogels: From Design to Performance as a Functional Dual Capacity Restorative Material and Build in Free Radical Defense: In-Vitro Studies. Open Journal of Stomatology, 4, 73-83. http://dx.doi.org/10.4236/ojst.2014.42013

[28] Roy, I. and Gupta, M.N. (2003) Smart Polymeric Materials: Emerging Biochemical Applications. Chemistry \& Biology, 10, 1161-1171. http://dx.doi.org/10.1016/j.chembiol.2003.12.004

[29] Katime, I., Novoa, R., de Apodaca, E.D. and Rodríguez, E. (2004) Release of Theophylline and Aminophylline from Acrylic Acid/n-Alkyl Methacrylate Hydrogels. Journal of Polymer Science Part A: Polymer Chemistry, 42, 2756-2765. http://dx.doi.org/10.1002/pola.20112

[30] Alam, H.B., Burris, D., Da Corta, J.A. and Rhee, P. (2005) Hemorrhage Control in the Battlefield: Role of New Hemostatic Agents. Military Medicine, 170, 63-69.

[31] Amiji, M.M. (1995) Permeability and Blood Compatibility Properties of Chitosan-Poly (Ethylene Oxide) Blend Membranes for Haemodialysis. Biomaterials, 16, 593-599. http://dx.doi.org/10.1016/0142-9612(95)93856-9

[32] Barrera, D.A., Zylstra, E., Lansbury, P.T. and Langer, R. (1993) Synthesis and RGD Peptide Modification of a New Biodegradable Copolymer: Poly(Lactic Acid-Co-Lysine). Journal of the American Chemical Society, 115, 1101011011. http://dx.doi.org/10.1021/ja00076a077

[33] Baumann, H. and Faust, V. (2001) Concepts for Improved Regioselective Placement of $O$-Sulfo, $N$-Sulfo, $N$-Acetyl, and $\mathrm{N}$-Carboxymethyl Groups in Chitosan Derivatives. Carbohydrate Research, 331, 43-57. http://dx.doi.org/10.1016/S0008-6215(01)00009-X

[34] Beena, M.S., Chandy, T. and Sharma, C.P. (1995) Heparin Immobilized Chitosan-Poly Ethylene Glycol Interpenetrating Network: Antithrombogenicity. Artificial Cells, Blood Substitutes and Biotechnology, 23, 175-192. http://dx.doi.org/10.3109/10731199509117937

[35] Bordenave, L.C., Baquey, R., Bareille, F., Lefebvre, C., Lauroua, V., Guerin, F., Rouais, N., More, C., Vergnes, C. and Anderson, J.M. (1995) Endothelial Cell Compatibility Testing of 3 Different Pelletanes. Journal of Biomedical Materials Research, 27, 1367-1381. http://dx.doi.org/10.1002/jbm.820271104

[36] Brown, M., Daya, M. and Worley, J. (2009) Experience with Chitosan Dressings in a Civilian EMS System. Journal of Emergency Medicine, 37, 1-7. http://dx.doi.org/10.1016/j.jemermed.2007.05.043

[37] Carreño-Gómez, B. and Duncan, R. (1997) Evaluation of the Properties of Soluble Chitosan and Chitosan Microspheres. International Journal of Pharmaceutics, 148, 231-240. http://dx.doi.org/10.1016/S0378-5173(96)04847-8

[38] Cenni, E., Ciapetti, G., Cervellati, M., Cavedagna, D., Falsone, G., Gamberini, S. and Pizzoferrato, A. (1996) Activation of the Plasma Coagulation System Induced by Some Biomaterials. Journal of Biomedical Materials Research Part A, 31, 145-148. 
Scientific Research Publishing (SCIRP) is one of the largest Open Access journal publishers. It is currently publishing more than 200 open access, online, peer-reviewed journals covering a wide range of academic disciplines. SCIRP serves the worldwide academic communities and contributes to the progress and application of science with its publication.

Other selected journals from SCIRP are listed as below. Submit your manuscript to us via either submit@scirp.org or Online Submission Portal.
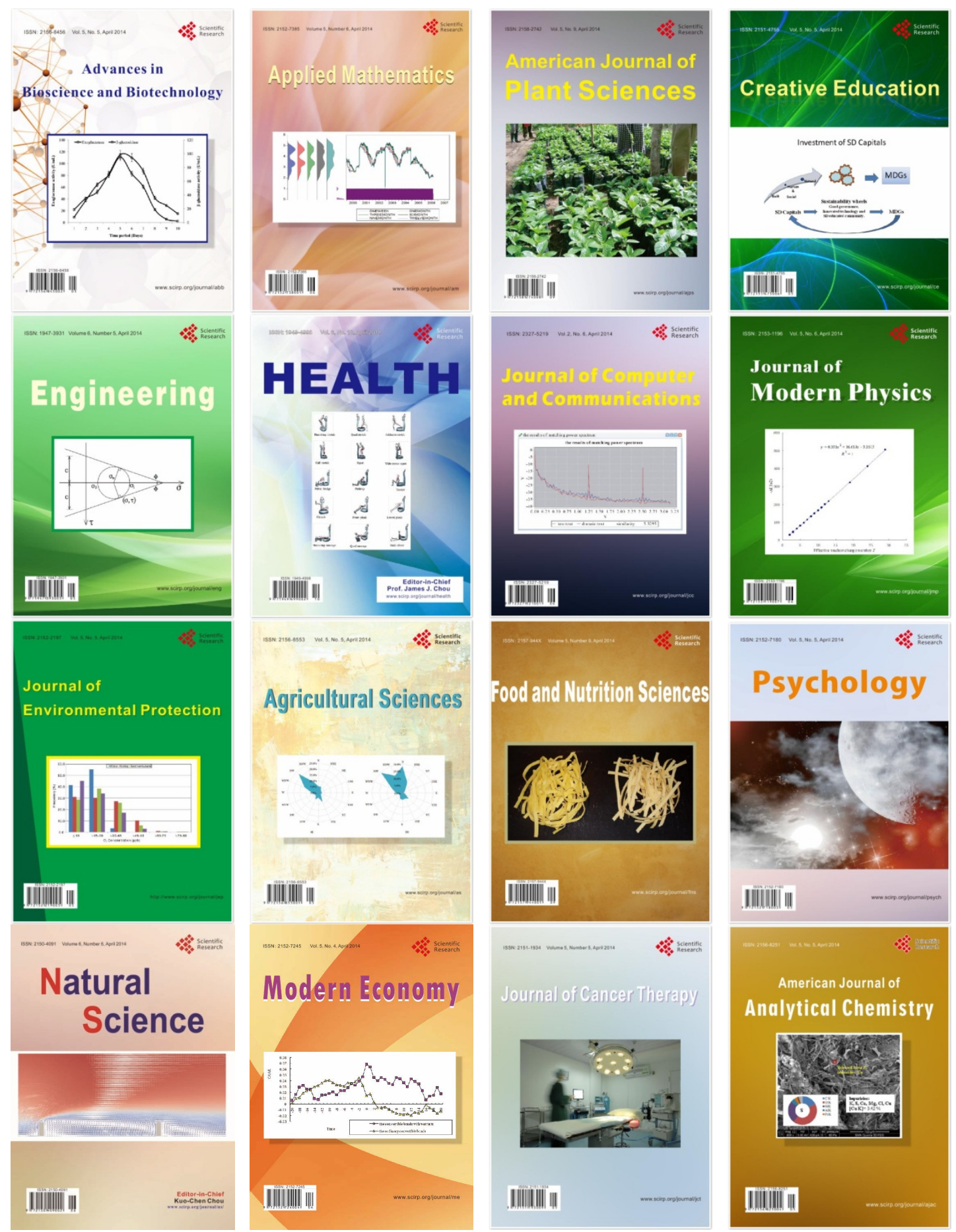